\title{
Observationally Equivalent Financial Mechanisms in an OLG Model with Spatial Separation
}

\author{
Eisei Ohtaki \\ Department of Economics, Kanagawa University, Kanagawa, Japan \\ Email: ohtaki@kanagawa-u.ac.jp
}

How to cite this paper: Ohtaki, E. (2021). Observationally Equivalent Financial Mechanisms in an OLG Model with Spatial Separation. Theoretical Economics Letters, 11, 226-238.

https://doi.org/10.4236/tel.2021.112016

Received: February 4, 2021

Accepted: April 4, 2021

Published: April 7, 2021

Copyright $\odot 2021$ by author(s) and Scientific Research Publishing Inc. This work is licensed under the Creative Commons Attribution International License (CC BY 4.0).

http://creativecommons.org/licenses/by/4.0/

\section{(c) (i) Open Access}

\begin{abstract}
This study introduces search frictions into a variant of overlapping generations environments, as in Smith (2002). In the model, this study compares financial intermediation to trading shares in decentralized secondary markets. The results show that under certain conditions, both financial mechanisms generate the same equilibrium outcome.
\end{abstract}

\section{Keywords}

Financial Intermediation, Search, Overlapping Generations Model, Spatial Separation, Friedman Rule

\section{Introduction}

Following Bryant (1980) and Diamond and Dybvig (1983), a body of literature that investigates the consequences of liquidity insurance with financial intermediaries has been persistently expanding. An important stream in such literature was provided by Smith (2002), who incorporated banks as described by Diamond and Dybvig (1983) into a monetary overlapping generations (OLG) model with spatial separation and showed the suboptimality of the Friedman rule (Friedman, 1969) ${ }^{1}$. In his model, there are two islands between which there is no communication (spatial friction). Furthermore, liquidity shocks are modeled by random relocation of agents. Then, a bank that is established by a coalition of agents provides deposit contracts, which play the role of liquidity insurance, to agents and relocated agents will withdraw their deposits before they move to the other island.

${ }^{1}$ An OLG model with spatial separation is first considered by Champ, Smith, and Williamson (1996). 
This type of financial intermediation has been blindly adopted in many previous studies, such as Schreft and Smith (2002), Haslag and Martin (2007), Matsuoka (2011), Ohtaki (2014), and Gupta and Makena (2020). However, even within the OLG model with spatial separation, such financial intermediation is not a unique financial mechanism. In contrast to previous studies, the aim of this study is to introduce another financial mechanism to the OLG model with spatial separation and compare its consequences to those of financial intermediation.

This study introduces the primary and secondary capital markets to the OLG model with spatial separation. Agents first enter primary and money markets, which are centralized, and invest their endowments in the production process and money. To simplify the argument, we assume that one share is issued for each unit of investment in the production process. Agents then buy or sell shares in the secondary market, which is assumed to be decentralized, rather than centralized. To construct decentralized secondary markets, agents must search for trading partners. In each decentralized secondary market of shares, a relocated agent will be a seller, and an agent who stays on the same island will be a buyer.

This study demonstrates the somewhat surprising result that, under certain conditions, equilibrium consequences under primary and secondary markets are the same as those in the presence of financial intermediation. This may imply the robustness of the results obtained in previous studies. In particular, this study shows the suboptimality of the Friedman rule.

Our findings contribute to the literature by comparing the direct and indirect finances. Jacklin (1987) has shown that, in a static economy as considered in Diamond and Dybvig (1983), direct and indirect finances attain the same allocation. On the other hand, in three-period OLG models, Bhattacharya and Padilla (1996) and Fulghieri and Rovelli (1998) argued that indirect finance is superior to direct finance in certain situations. The observational equivalence between direct and indirect finances in this study can be interpreted as a restatement of Jacklin's result in a two-period OLG model.

The remainder of this paper is organized as follows. Section 2 introduces the model's ingredients. Section 3 considers financial intermediation as a benchmark. Section 4 considers an economy with primary and secondary markets. Section 5 provides the concluding remarks. Proofs of propositions are presented in the Appendix.

\section{Ingredients of the Model}

This section presents ingredients of the model. Time is indexed by $t$ and runs discretely from minus infinity to plus infinity. Each period is divided into two stages; 1 and 2. Two island exist at distinct locations, and there is no communication between them. In stage 1 of each period, a single perishable commodity, called the consumption good, exists on each island. In addition, an intertemporal production technology exists, whereby $k \geq 0$ units stored at stage 1 of date $t$ 
generates $(1+\bar{r}) k$ units of the consumption good at stage 1 of date $t+1$. The net rate of return of this storage technology, $\bar{r} \geq 0$, is a known constant ${ }^{2}$.

At the beginning of each period, a new generation, consisting of a continuum of ex-ante identical agents with a unit mass, appears on each island and exists for three consecutive stages. Agents born in stage 1 of period $t$ are young in period $t$, or their first and second stages, and old in period $t+1$ or their third stage. They aim to maximize their utility $u\left(c_{t+1}\right)$ gained from consumption, $c_{t+1}$, during the third stage of their lives, whereas they are endowed with $\bar{w}>0$ units of the consumption good in the first stage and none in the second and third stages. The utility function $u: \mathbb{R}_{+} \rightarrow \mathbb{R}$ is strictly monotone increasing, strictly concave, and twice continuously differentiable on the interior of its domain and satisfies that $\lim _{c \downarrow 0} u^{\prime}(c)=\infty$.

Moreover, agents in the same cohort at each location are ex ante identical but learn their types, $\alpha$ or $\beta$, at the start of the second stage. The ex post distribution of agents on $S:=\{\alpha, \beta\}$ is represented by the probability measure $\lambda$ on $S$, where $\lambda_{s}>0$ for each $s \in S$. To simplify the argument, we assume that half of the agents become type $\alpha$ agents and the other half become type $\beta$ agents, that is, $\lambda_{\alpha}=\lambda_{\beta}=0.5$. At the end of each period, the type $\alpha$ agents on each island move to the other island, whereas the type $\beta$ agents stay on the same island. It is assumed that type $\alpha$ agents, called movers, cannot receive the return of the storage investment, whereas type $\beta$ agents, called nonmovers, can do so.

In the economy, a durable and intrinsically useless object referred to as money also exists. Money is issued by the central bank and its per capita stock at date $t$ is denoted by $M_{t}$. The per capita stock of money follows the equation $M_{t}=(1+\mu) M_{t}-1$ for each period $t$, where $\mu$ is the constant growth rate of per capita money stock and chosen by the central bank. Each young agent born in period $t$ receives the newly issued money, $\Delta_{t}:=M_{t}-M_{t-1}=\mu M_{t} /(1+\mu)$, at the beginning of the period. To guarantee the nonnegativity of the net nominal interest rate, it is assumed that $\mu \geq-\bar{r} /(1+\bar{r})$.

\section{Equilibrium with Financial Intermediation}

As a benchmark, we first consider an equilibrium with financial intermediaries as in Smith (2002).

\subsection{Timing of Trades}

At the beginning of each period $t$, young agents cooperate with each other and establish a bank. They then deposit a certain amount of their after-tax/transfer

\footnotetext{
${ }^{2} \mathrm{We}$ can consider several backgrounds to our production technology; one called the storage technol$o g y$, and one that is a linear production function $F(k, L)=\bar{r} k+\bar{w} L$, where $\bar{w}$ is introduced below as the initial endowment. Finally, the economy considered here may be a small-open economy with completely free capital mobility. $\bar{r}$ can then be interpreted as the net interest rate of the world and $\bar{W}$ is defined by $\bar{w}:=f(\bar{k})-\overline{r k}$ for some per-capita production function $f$ with $f^{\prime}>0$ and $f^{\prime \prime}<0$ and the Inada condition, where $\bar{k}$ is defined uniquely by $\bar{k}:=\left(f^{\prime}\right)^{-1}(\bar{r})$.
} 
endowments into their bank. During stage 1 of the period, the bank and the old agents meet in a centralized spot market (of money). At this stage, the bank invests its deposits in storage technology and money.

In stage 2 of the period, young agents learn their types, and in the second period, movers lose their connection to their banks. As a result, movers withdraw their deposits during this stage, and nonmovers withdraw their deposits during the third stage. We assume that the centralized spot market at stage 1 of each period $t$ is competitive and denoted by $P_{t}$ the nominal price of the consumption good in the market. We also use $q_{t}$ to denote the per capita real money balance in each period $t$, that is, $q_{t}=M_{t} / P_{t}$. We define the inflation rate by $\pi_{t+1}:=P_{t+1} / P_{t}-1$ and the nominal interest rate by $i_{t+1}:=(1+\bar{r})\left(1+\pi_{t+1}\right)-1$ for each $t$.

\subsection{Definition of Equilibrium}

We begin by considering the behavior of the banks. The bank established in period $t$ is assumed to propose a "contract" to its agents. Here, a contract is a triplet $\left(d_{t}, c_{t+1},\left(k_{t}+1, m_{t}\right)\right)$ of the per-capita deposit $d_{t}$, a second-period contingent consumption plan $c_{t+1}=\left(c_{t+1}^{\alpha}, c_{t+1}^{\beta}\right)$, and portfolio plans $\left(k_{t+1}, m_{t}\right)$, which include a pair of per capita investments in storage technology and money. The first constraint for the bank is the restriction on deposits. Because each agent's after-tax/transfer endowment is $\bar{w}+\tau_{t}$, it must hold that

$$
d_{t} \leq \bar{w}+\tau_{t}
$$

where $\tau_{t}:=\Delta_{t} / P_{t}=[\mu /(1+\mu)] q_{t}$. The bank then invests in storage technology and money. Its portfolio constraint is given by

$$
k_{t+1}+\frac{m_{t}}{P_{t}} \leq d_{t}
$$

where $k_{t+1} \geq 0$ and $m_{t} / P_{t} \geq 0$ are the per capita amounts of the investments in storage technology and money, respectively.

Because the returns of the investments must meet the total consumption, the following budget constraint should be considered:

$$
c_{t+1}^{\alpha} \lambda_{\alpha}+c_{t+1}^{\beta} \lambda_{\beta} \leq(1+\bar{r}) k_{t+1}+\frac{m_{t}}{P_{t+1}} .
$$

This inequality can be rewritten as

$$
(1+\bar{r}) k_{t+1}+\frac{m_{t}}{P_{t+1}}-\left[c_{t+1}^{\alpha} \lambda_{\alpha}+c_{t+1}^{\beta} \lambda_{\beta}\right] \geq 0
$$

which can be interpreted as an individual rationality (or participation) constraint for the bank.

The final restriction is the liquidity constraint. Because movers lose their connection to their banks in the second period, they withdraw their money after they learn their types. Therefore, at the end of the first period, the bank must have sufficient liquidity to meet the needs of the movers: 


$$
C_{t+1}^{\alpha} \lambda_{\alpha} \leq \frac{m_{t}}{P_{t+1}} .
$$

Finally, we assume that the bank adopts the welfare function $U\left(c_{t+1}\right)=\sum_{s \in S} u\left(c_{t+1}^{s}\right) \lambda_{s}$, which is equal to each agent's expected lifetime utility function, as its objective function. A contract $\left(d_{t}, c_{t+1},\left(k_{t+1}, m_{t}\right)\right)$ is said to be optimal if it maximizes $U\left(c_{t+1}\right)$ subject to Equations (1) - (4).

We can now define an equilibrium with financial intermediation as follows:

Definition 1. A monetary equilibrium with financial intermediation is defined by a sequence $\left\{q_{t}^{*}, k_{t+1}^{*}\right\}_{t=-\infty}^{\infty}$ of the pair of positive per capita real money balances $q_{t}>0$ and storage investments $k_{t+1}^{*} \geq 0$ such that there exists some sequence $\left\{d_{t}^{*}, c_{t+1}^{*}, m_{t}^{*}\right\}_{t=-\infty}^{\infty}$ of triplets of deposits $d_{t}^{*}$, second-period consumption $c_{t+1}^{*}$, and money holdings $m_{t}^{*}$ satisfying that, for each period $t$,

MEF1: $\left(d_{t}^{*}, c_{t+1}^{*},\left(k_{t+1}^{*}, m_{t}^{*}\right)\right)$ is an optimal contract, that is, it maximizes

$$
U\left(c_{t+1}\right)=u\left(c_{t+1}^{\alpha}\right) \lambda_{\alpha}+u\left(c_{t+1}^{\beta}\right) \lambda_{\beta}
$$

subject to Equations (1) - (4) given $P_{\tau}=M_{\tau} / q_{\tau}^{*}$ for $\tau=t, t+1$, and

MEF2: $m_{t}^{*}=M_{t}$.

Moreover, it is a monetary steady state (with financial intermediation) if it is independent of period $t$, that is, if there exists some $(q, k) \in \mathbb{R}_{++} \times \mathbb{R}_{+}$such that $\left(q_{t}^{*}, k_{t}^{*}\right)=(q, k)$ for each period $t$.

\subsection{Characterization}

This subsection characterizes the monetary equilibrium with financial intermediation. We first verify that, at any monetary equilibrium, it must hold that $i_{t+1} \geq 0$ for each $t$. In fact, the combination of Equations (2) and (3) implies the lifetime budget constraint (for banks) such that

$$
\frac{c_{t+1}^{\alpha} \lambda_{\alpha}+c_{t+1}^{\beta} \lambda_{\beta}}{1+\bar{r}} \leq d_{t}+\left(\frac{1}{1+\bar{r}} \frac{P_{t}}{P_{t+1}}-1\right) \frac{m_{t}}{P_{t}}=d_{t}-\frac{i_{t+1}}{1+i_{t+1}} \frac{m_{t}}{P_{t}},
$$

where $i_{t} /\left(1+i_{t+1}\right)$ can be interpreted as the cost per unit of the money holdings. The bank established in period $t$ then chooses $+\infty$ as $m_{t}$ if $-1 \leq i_{t+1}<0^{3}$, which contradicts the fact that $m_{t}=M_{t}$ at any monetary equilibrium. Therefore, it must hold that $i_{t+1} \geq 0$ for each period $t$ at any monetary equilibrium. This is equivalent to $1+\mu \geq 1 /(1+\bar{r})$ in a monetary steady state.

In addition, note that the bank established in period $t$ wishes to keep the amount of money holding as small as possible if $i_{t+1}>0$. In this case, the liquidity constraint (4) plays an important role. This prevents banks from setting the amount of money to 0 . In fact, the liquidity constraint must hold with equality because the movers' consumption at a monetary equilibrium is positive due to the boundary condition imposed on $u$. On the other hand, when $i_{t+1}=0$, investments in storage technology and money are completely substitutable because their rates of return become equal to each other. As a result, there might be mul${ }^{3}$ Note that $1+i_{t+1}=(1+\bar{r})\left(1+\pi_{t+1}\right) \geq 0$. 
tiple monetary equilibria, even in the class of monetary steady states. Such indeterminacy of monetary steady states is not robust because, as shown in later, a monetary steady state is unique when $i_{t+1}>0$. Therefore, we identify the monetary steady state such that $i_{t+1}=0$ with a limiting case as $i_{t+1} \downarrow 0$.

Now, suppose that $i_{t+1}>0$. Given the previous arguments, a solution to the optimization problem for each bank can be characterized by

$$
\frac{1}{1+\mu} q_{t+1} u^{\prime}\left(\frac{1}{\lambda_{\alpha}} \frac{1}{1+\mu} q_{t+1} \frac{m_{t}}{M_{t}}\right)=(1+\bar{r}) q_{t} u^{\prime}\left(\frac{1+\bar{r}}{\lambda_{\beta}}\left[\bar{w}+\frac{\mu}{1+\mu} q_{t}-q_{t} \frac{m_{t}}{M_{t}}\right]\right)
$$

and Equations (1) - (4) with equality. Because at a monetary steady state, it must hold that $m_{t}=M_{t}$, we can obtain the following proposition:

Proposition 1. A monetary equilibrium $\left\{q_{t}^{*}, k_{t+1}^{*}\right\}_{t=-\infty}^{\infty}$ with financial intermediation, if any, is characterized by

$$
\frac{1}{1+\mu} q_{t+1}^{*} u^{\prime}\left(\frac{1}{\lambda_{\alpha}} \frac{1}{1+\mu} q_{t+1}^{*}\right)=(1+\bar{r}) q_{t}^{*} u^{\prime}\left(\frac{1+\bar{r}}{\lambda_{\beta}}\left[\bar{w}-\frac{1}{1+\mu} q_{t}^{*}\right]\right)
$$

and $k_{t+1}^{*}=\bar{w}-q_{t}^{*} /(1+\mu)$ for each period $t$.

As a corollary of this proposition, we can say that a monetary steady state, denoted by $(q, k) \in \mathbb{R}_{++} \times \mathbb{R}_{+}$, if any, is characterized by

$$
\frac{1}{1+\mu} u^{\prime}\left(\frac{1}{\lambda_{\alpha}} \frac{1}{1+\mu} q\right)=(1+\bar{r}) u^{\prime}\left(\frac{1+\bar{r}}{\lambda_{\beta}}\left[\bar{w}-\frac{1}{1+\mu} q\right]\right)
$$

and $k=\bar{w}-q /(1+\mu)$. We use this characterization to obtain the observational equivalence between equilibrium outcomes under different financial mechanisms.

\section{Equilibrium with Primary and Secondary Markets}

In contrast to previous works such as Smith (2002) and Haslag and Martin (2007), this section introduces the primary and secondary markets of capital into the model. Our secondary markets are decentralized, and agents must, therefore, search for trading partners ${ }^{4}$.

\subsection{Timing of Trades}

In stage 1 of each period $t$, young and old agents meet in a centralized spot market. At this stage, young agents invest their after-tax/transfer endowment in storage technology and money. We assume that one share is issued for each unit of storage investment. Therefore, investment in storage technology may be interpreted as issuing new shares in the primary market. In stage 2 of that period, young agents match in pairs. This matching is random, but without loss of generality, a type $\alpha$ agent is assumed to meet a type $\beta$ agent. In each pairwise meeting (decentralized secondary market), each agent's portfolio is common knowledge and the surplus from the trade is split by generalized Nash bargain-

${ }^{4}$ The idea of embedding search into an OLG model was introduced by Zhu (2008). 
ing. Each agent consumes returns from money or storage investments in the third stage. We assume that the centralized spot market of each period $t$ is competitive, and we use $P_{t}$ to denote the nominal price of the consumption good in the market. We also denote by $q_{t}$ the per capita real money balance in the centralized market in each period $t$, that is, $q_{t}=M_{t} / P_{t}$. We define the inflation rate by $\pi_{t+1}:=P_{t+1} / P_{t}-1$ and the nominal interest rate by $i_{t+1}:=(1+\bar{r})\left(1+\pi_{t+1}\right)-1$ for each $t$

\subsection{Definition of Equilibrium}

Because agents are ex ante identical, we consider a symmetric situation with respect to young agents' choices in their first stage. At stage 1 of each period $t$, young agents invest their after-tax/transfer endowments in the storage technology and money. This portfolio constraint is described by

$$
k_{t+1}+\frac{m_{t}}{P_{t}} \leq \bar{w}+\tau_{t}
$$

where $k_{t+1} \geq 0$ and $m_{t} / P_{t} \geq 0$ are investments in storage technology and money, respectively, and $\tau_{t}:=\Delta_{t} / P_{t}$. Then, each young agent enters a pairwise meeting with $k_{t+1}$ and $m_{t}$. The outcome of a pairwise meeting between type $\alpha$ and type $\beta$ agents is assumed to be a maximizer of the following generalized Nash bargaining problem:

$$
\begin{gathered}
\max _{c_{t+1}^{\alpha}, c_{t+1}^{\beta}}\left[u\left(c_{t+1}^{\alpha}\right)-u\left(d_{t+1}^{\alpha}\right)\right]^{\theta}\left[u\left(c_{t+1}^{\beta}\right)-u\left(d_{t+1}^{\beta}\right)\right]^{1-\theta} \\
\text { subject to } c_{t+1}^{\alpha}+c_{t+1}^{\beta} \leq 2\left[(1+\bar{r}) k_{t+1}+\frac{m_{t}}{P_{t+1}}\right], \\
c_{t+1}^{\alpha} \leq 2 \frac{m_{t}}{P_{t+1}}, \\
d_{t+1}^{\alpha}=\frac{m_{t}}{P_{t+1}}, \\
d_{t+1}^{\beta}=(1+\bar{r}) k_{t+1}+\frac{m_{t}}{P_{t+1}}
\end{gathered}
$$

where $\theta \in(0,1]$ is the bargaining power of the type $\alpha$ agent. Here, Equation (7) provides the set of possible pairs $\left(c_{t+1}^{\alpha}, c_{t+1}^{\beta}\right)$ of the consumption of type $\alpha$ and $\beta$ agents, Equation (8) represents the liquidity constraint for the type $\alpha$ agent $^{5}$, and Equations (9) and (10) represent consumption at the disagreement point. We then denote the solution to this bargaining problem, which is often called the generalized Nash bargaining solution, by

$$
\varphi\left(k_{t+1}, m_{t} / P_{t+1}\right)=\left(\varphi^{\alpha}\left(k_{t+1}, m_{t} / P_{t+1}\right), \varphi^{\beta}\left(k_{t+1}, m_{t} / P_{t+1}\right)\right) .
$$

Note that, in this bargaining, agent $\alpha$ sells the share of the storage investment

${ }^{5}$ Recall that type $\alpha$ agents, that is, movers, cannot receive the return of storage technology. 
and agent $\beta$ buys it.

We can now define an equilibrium with search as follows:

Definition 2. A monetary equilibrium with search is defined by a sequence $\left\{q_{t}^{*}, k_{t+1}^{*}\right\}_{t=-\infty}^{\infty}$ of the pair of positive per capita real money balances $q_{t}>0$ and storage investments $k_{t+1}^{*} \geq 0$ such that there exists some sequence $\left\{m_{t}^{*}\right\}_{t=-\infty}^{\infty}$ of money holdings $m_{t}^{*}$ satisfying that, for each period $t$,

MES1: $\left(k_{t+1}^{*}, m_{t}^{*}\right)$ maximizes

$$
u\left(\varphi^{\alpha}\left(k_{t+1}, m_{t} / P_{t+1}\right)\right) \lambda_{\alpha}+u\left(\varphi^{\beta}\left(k_{t+1}, m_{t} / P_{t+1}\right)\right) \lambda_{\beta}
$$

subject to Equation (5) given $P_{\tau}=M_{\tau} / q_{\tau}^{*}$ for $\tau=t, t+1$, and

MES2: $m_{t}^{*}=M_{t}$.

Moreover, it is a monetary steady state (with search) if it is independent of period $t$, that is, there exists some $(q, k) \in \mathbb{R}_{++} \times \mathbb{R}_{+}$such that $\left(q_{t}^{*}, k_{t}^{*}\right)=(q, k)$ for each period $t$.

\subsection{Observationally Equivalence}

To characterize a monetary equilibrium with search, we first assume that agent $a$ s bargaining power is equal to one, that is, $\theta=1$. The generalized Nash bargaining described by Equations (6) - (10) can then be rewritten as the following problem:

$$
\begin{gathered}
\max _{c_{t+1}^{\alpha}, c_{t+1}^{\beta}} u\left(c_{t+1}^{\alpha}\right) \\
\text { subject to } c_{t+1}^{\alpha}+c_{t+1}^{\beta} \leq 2\left[(1+\bar{r}) k_{t+1}+\frac{m_{t}}{P_{t+1}}\right], \\
c_{t+1}^{\alpha} \leq 2 \frac{m_{t}}{P_{t+1}}, \\
u\left(c_{t+1}^{\beta}\right) \geq u\left((1+\bar{r}) k_{t+1}+\frac{m_{t}}{P_{t+1}}\right),
\end{gathered}
$$

where the last inequality is the participation constraint for nonmovers. One can immediately investigate that a solution to this problem is as follows:

$$
\left(c_{t+1}^{\alpha}, c_{t+1}^{\beta}\right)=\left(2 \frac{m_{t}}{P_{t+1}}, 2(1+\bar{r}) k_{t+1}\right)
$$

provided that $m_{t} / P_{t+1} \leq(1+\bar{r}) k_{t+1}$, which is true in monetary steady states under nonnegative nominal interest rates. Furthermore, because of the continuity of the Nash product (6) with respect to $\theta$, we can say that the above $\left(c_{t+1}^{\alpha}, c_{t+1}^{\beta}\right)$ is also the solution to the generalized Nash bargaining problem, provided that $\theta$ is sufficiently close to 1 .

We can now characterize a monetary steady state in this economy.

Proposition 2. A monetary steady state $(q, k)$ with search, if any, is characterized by the following. 


$$
\frac{1}{1+\mu} u^{\prime}\left(\frac{1}{\lambda_{\alpha}} \frac{1}{1+\mu} q\right)=(1+\bar{r}) u^{\prime}\left(\frac{1+\bar{r}}{\lambda_{\beta}}\left[\bar{w}-\frac{1}{1+\mu} q\right]\right)
$$

and $k=\bar{w}-q /(1+\mu)$ if $\theta$ is sufficiently close to 1 .

Note that Equation (16) implies that, in a monetary steady state, movers' consumption is less than or equal to that of nonmovers. This follows from the strict concavity of $u$ and the fact that $u^{\prime}\left(c^{\alpha}\right)=(1+\bar{r})(1+\mu) u^{\prime}\left(c^{\beta}\right) \geq u^{\prime}\left(c^{\beta}\right)$. This guarantees the solution to the Nash bargaining problem with $\theta=1$. In addition, note that, without any doubt, the characterization in the last proposition is equivalent to that obtained in the previous section. Therefore, we can conclude that the financial mechanisms considered in Sections 3 and 4 are observationally equivalent.

\subsection{Properties of Monetary Steady State}

We close this section by discussing several properties of monetary steady states (with search). The following properties are well known in the existing literature on the OLG model with spatial separation and financial intermediation. However, in contrast to previous studies, nearly all of which assumed a constant relative risk aversion with an index less than or equal to one, we show the same properties under a more general class of utility functions. The first proposition guarantees the existence and uniqueness of a monetary steady state.

Proposition 3. For each $\mu \geq-\bar{r} /(1+\bar{r})$, Equation (16) has a unique solution $q(\sigma)$, where $\sigma:=1+\mu$ is a gross rate of growth of the money stock.

The second proposition provides the relation between $\sigma=1+\mu$ and $q(\sigma) / \sigma$. This proposition is used in the proof of Proposition 5 .

Proposition 4. Let $\rho(\sigma):=q(\sigma) / \sigma$. Then, for each $\sigma \geq 1 /(1+\bar{r}), \rho^{\prime}(\sigma)<0$.

Finally, we examine the optimality of the Friedman rule. We define the equilibrium welfare given the gross rate of growth of the money stock, $\sigma=1+\mu$, by

$$
W(\sigma):=U\left(c^{\alpha}(\sigma), c^{\beta}(\sigma)\right)
$$

where

$$
c^{\alpha}(\sigma):=\frac{1}{\lambda_{\alpha}} \rho(\sigma) \text { and } c^{\beta}(\sigma):=\frac{1+\bar{r}}{\lambda_{\beta}}[\bar{w}-\rho(\sigma)]
$$

reflect the consumption of movers and nonmovers, respectively, at a monetary steady state. The Friedman rule requires that the net nominal interest rate is equal to zero, which is equivalent to $\mu^{f}=-\bar{r} /(1+\bar{r})$ in our model. We must examine whether $\mu^{f}$ maximizes $W(\sigma)$, which allows us to show the suboptimality of the Friedman rule.

Proposition 5. The optimal gross rate of growth of the money stock, which maximizes $W(\sigma)$, is $\sigma^{* *}=1$, which implies the suboptimality of the Friedman rule.

Note that the condition that $\sigma^{* *}=1$ corresponds to $\mu=0$, which is not equal to $\mu^{f}$. 


\section{Concluding Remarks}

The OLG model with spatial separation, developed by Champ, Smith, and Williamson (1996) and Smith (2002), is a very tractable model for describing situations in which agents face liquidity shortages. Although previous works assumed that agents remedy liquidity shortages via liquidity insurance provided by financial intermediaries such as banks, this study considers that agents who face a liquidity shortage seek trading partners and liquidate their share of returns of the intertemporal production technology. By comparing these two financial mechanisms, this study shows that such indirect and direct finances yield the same equilibrium outcomes under appropriate conditions.

Our observational equivalence is based on several technical requirements. First, the sizes of agents who face and do not face a liquidity shortage must be the same. If they are not, some agents lose opportunities for liquidation, and the economy will be worse off than in this study. Second, the bargaining power of agents who face a liquidity shortage must be sufficiently close to unity. If the bargaining power of agents who face a liquidity shortage is sufficiently close to zero, for example, Equation (15) is no longer the solution to the Nash bargaining problem, and the equilibrium outcomes depart from those in this study. A detailed study of the model without the presented technical restrictions is left for future research.

\section{Acknowledgements}

The author thanks to an anonymous referee for helpful comments.

\section{Conflicts of Interest}

The author declares no conflicts of interest regarding the publication of this paper.

\section{References}

Bhattacharya, S., \& Padilla, A. J. (1996). Dynamic Banking: A Reconsideration. Review of Financial Studies, 9, 1003-1032. https://doi.org/10.1093/rfs/9.3.1003

Bryant, J. (1980). A Model of Reserves, Bank Runs, and Deposit Insurance. Journal of Banking and Finance, 4, 335-344. https://doi.org/10.1016/0378-4266(80)90012-6

Champ, B., Smith, B. D., \& Williamson, S. D. (1996). Currency Elasticity and Banking Panics: Theory and Evidence. Canadian Journal of Economics, 29, 828-864. https://doi.org/10.2307/136217

Diamond, D., \& Dybvig, P. (1983). Bank Runs, Deposit Insurance and Liquidity. Journal of Political Economy, 91, 401-419. https://doi.org/10.1086/261155

Friedman, M. (1969). The Optimum Quantity of Money and Other Essays. Chicago: Aldine.

Fulghieri, P., \& Rovelli, R. (1998). Capital Markets, Financial Intermediaries, and Liquidity Supply. Journal of Banking and Finance, 22, 1157-1179. https://doi.org/10.1016/S0378-4266(98)00053-3

Gupta, R., \& Makena, P. (2020). Growth Dynamics, Multiple Equilibria, and Local Inde- 
terminacy in an Endogenous Growth Model of Money, Banking and Inflation Targeting. Economies, 8, 1-14. https://doi.org/10.3390/economies8010022

Haslag, J. H., \& Martin, A. (2007). Optimality of the Friedman Rule in an Overlapping Generations Model with Spatial Separation. Journal of Money, Credit and Banking, 39, 1741-1758. https://doi.org/10.1111/j.1538-4616.2007.00085.x

Jacklin, C. J. (1987). Demand Deposits, Trading Restrictions, and Risk Sharing. In E. C. Prescott, \& N. Wallace (Eds.), Contractual Arrangements for Intertemporal Trade (pp. 26-47). Minneapolis, MN: University of Minnesota Press.

Matsuoka, T. (2011). Monetary Policy and Banking Structure. Journal of Money, Credit and Banking, 43, 1109-1129. https://doi.org/10.1111/j.1538-4616.2011.00419.x

Ohtaki, E. (2014). Asymmetric Liquidity Shocks and Optimal Monetary Policy. Economics Bulletin, 34, 1068-1080.

Schreft, S., \& Smith, B. D. (2002). The Conduct of Monetary Policy with a Sharing Stock of Government Debt. Journal of Money, Credit and Banking, 34, 848-882. https://doi.org/10.1353/mcb.2002.0021

Smith, B. D. (2002). Monetary Policy, Banking Crises, and the Friedman Rule. American Economic Review Papers and Proceedings, 92, 128-134. https://doi.org/10.1257/000282802320189122

Zhu, T. (2008). An Overlapping Generations Model with Search. Journal of Economic Theory, 142, 318-331. https://doi.org/10.1016/j.jet.2007.01.020 


\section{Appendix: Proofs of Propositions}

Proof of Proposition 1. Suppose first that $i_{t+1}>0$. Then, as argued as in the second paragraph in Subsection 3.3, the liquidity constraint (4) holds with equality. So, the optimization problem of a bank can be rewritten as

$$
\begin{gathered}
\max U\left(c_{t+1}^{\alpha}, c_{t+1}^{\beta}\right) \\
\text { subject to } k_{t+1}+\frac{m_{t}}{P_{t}}=\bar{w}+\tau_{t}, c_{t+1}^{\alpha}=\frac{1}{\lambda_{\alpha}} \frac{m_{t}}{P_{t+1}}, c_{t+1}^{\beta}=\frac{1+\bar{r}}{\lambda_{\beta}} k_{t+1} .
\end{gathered}
$$

It is immediate to show that a solution to this problem is characterized by

$$
\frac{1}{1+\mu} q_{t+1} u^{\prime}\left(\frac{1}{\lambda_{\alpha}} \frac{1}{1+\mu} q_{t+1} \frac{m_{t}}{M_{t}}\right)=(1+\bar{r}) q_{t} u^{\prime}\left(\frac{1+\bar{r}}{\lambda_{\beta}}\left[\bar{w}+\frac{\mu}{1+\mu} q_{t}-q_{t} \frac{m_{t}}{M_{t}}\right]\right)
$$

with constraints. Because it must hold at a monetary equilibrium with financial intermediation that $m_{t}=M_{t}$, we can conclude that a monetary equilibrium $\left\{q_{t}^{*}, k_{t+1}^{*}\right\}_{t=-\infty}^{\infty}$, if any, is characterized by

$$
\frac{1}{1+\mu} q_{t+1}^{*} u^{\prime}\left(\frac{1}{\lambda_{\alpha}} \frac{1}{1+\mu} q_{t+1}^{*}\right)=(1+\bar{r}) q_{t}^{*} u^{\prime}\left(\frac{1+\bar{r}}{\lambda_{\beta}}\left[\bar{w}-\frac{1}{1+\mu} q_{t}^{*}\right]\right)
$$

and $k_{t+1}^{*}=\bar{w}-q_{t}^{*} /(1+\mu)$ for each period $t$.

Q.E.D.

Proof of Proposition 2. Assume that $\theta$ is sufficiently close to 1 . Then, given the solution

$$
\left(c_{t+1}^{\alpha}, c_{t+1}^{\beta}\right)=\left(2 \frac{m_{t}}{P_{t+1}}, 2(1+\bar{r}) k_{t+1}\right)=\left(\frac{1}{\lambda_{\alpha}} \frac{m_{t}}{P_{t+1}}, \frac{1}{\lambda_{\beta}}(1+\bar{r}) k_{t+1}\right)
$$

to the Nash bargaining, each agent maximizes

$$
U\left(\frac{1}{\lambda_{\alpha}} \frac{m_{t}}{P_{t+1}}, \frac{1}{\lambda_{\beta}}(1+\bar{r}) k_{t+1}\right)
$$

subject to $k_{t+1}+m_{t} / P_{t} \leq \bar{w}+\tau_{t}$. Now, it is immediate to show that a solution to this problem is characterized by

$$
\frac{1}{1+\mu} q_{t+1} u^{\prime}\left(\frac{1}{\lambda_{\alpha}} \frac{1}{1+\mu} q_{t+1} \frac{m_{t}}{M_{t}}\right)=(1+\bar{r}) q_{t} u^{\prime}\left(\frac{1+\bar{r}}{\lambda_{\beta}}\left[\bar{w}+\frac{\mu}{1+\mu} q_{t}-q_{t} \frac{m_{t}}{M_{t}}\right]\right)
$$

with $k_{t+1}=\bar{w}+\tau_{t}-m_{t} / P_{t}$. Because it must hold at a monetary steady state with search that $m_{t}=M_{t}$ and that variables are time-invariant, we can conclude that a monetary steady state $(q, k)$, if any, is characterized by

$$
\frac{1}{1+\mu} u^{\prime}\left(\frac{1}{\lambda_{\alpha}} \frac{1}{1+\mu} q\right)=(1+\bar{r}) u^{\prime}\left(\frac{1+\bar{r}}{\lambda_{\beta}}\left[\bar{w}-\frac{1}{1+\mu} q\right]\right)
$$

and $k=\bar{w}-q /(1+\mu)$.

Proof of Proposition 3. Let

$$
\operatorname{MRS}(q):=\frac{u^{\prime}\left(\frac{1}{\lambda_{\alpha}} \frac{1}{1+\mu} q\right)}{u^{\prime}\left(\frac{1+\bar{r}}{\lambda_{\beta}}\left[\bar{w}-\frac{1}{1+\mu} q\right]\right)}
$$


which is monotone decreasing and continuous with respect to $q$ and satisfies that $\lim _{q \downarrow 0} \operatorname{MRS}(q)=\infty$ and $\lim _{q^{\uparrow}(1+\mu) \overline{\mathrm{w}}} \operatorname{MRS}(q)=0$. Therefore, there is uniquely some $q(1+\mu)$ such that

$$
\operatorname{MRS}(q(1+\mu))=(1+\bar{r})(1+\mu) \geq 1 .
$$

This $q(1+\mu)$ is obviously a solution to Equation (16).

Proof of Proposition 4. For each $\sigma \geq 1 /(1+\bar{r})$, it must hold that

$$
\operatorname{MRS}(q(\sigma))=(1+\bar{r}) \sigma .
$$

Because $M R S$ is monotone decreasing, an increase in $\sigma$ in the right-hand side of this equation must imply a decreasing in $q(\sigma)$. Q.E.D.

Proof of Proposition 5. Because $q^{\prime}(\sigma)<0$ and $q(\sigma)$ satisfy Equation (16), it holds that

$$
\begin{aligned}
W^{\prime}(\sigma) & =u^{\prime}\left(c^{\alpha}(\sigma)\right) \rho^{\prime}(\sigma)-(1+\bar{r}) u^{\prime}\left(c^{\beta}(\sigma)\right) \rho^{\prime}(\sigma) \\
& =\rho^{\prime}(\sigma)\left(1-\frac{1}{\sigma}\right) u^{\prime}\left(c^{\alpha}(\sigma)\right)\left\{\begin{array}{l}
> \\
= \\
<
\end{array}\right\} 0 \Leftrightarrow \sigma\left\{\begin{array}{l}
< \\
= \\
>
\end{array}\right\} 1 .
\end{aligned}
$$

This implies that $\sigma^{* *}=1$ maximizes $W(\sigma)$.

Q.E.D. 